\title{
Tobacco and tobacco branding in films most popular in the UK from 1989 to 2008
}

\author{
Ailsa Lyons, Ann McNeill, Yilu Chen, John Britton
}

\section{See Editorial, p 377}

UK Centre for Tobacco Control Studies, Division of Epidemiology and Public Health, School of Community Health Sciences, University of Nottingham, Nottingham, UK

\section{Correspondence to}

Ms Ailsa Lyons, Clinical Sciences Building, Phase 2, UK Centre for Tobacco Control Studies, Division of

Epidemiology and Public Health, School of Community Health Sciences, University of Nottingham, Nottingham NG5 1PB, UK; mcxal4@nottingham. ac.uk

Received 4 November 2009 Accepted 24 January 2010

\section{ABSTRACT}

Background Tobacco promotion is now tightly restricted in the UK and many other countries, but tobacco imagery including brand appearances in the media remain potentially powerful drivers of smoking uptake among children and young people. The extent to which tobacco imagery and specific products have appeared in the most popular films viewed in the UK over 20 years has been measured, in relation to year of release, the age certification allocated to the film by the British Board of Film Classification (BBFC), country of origin and other characteristics.

Methods Occurrence of tobacco intervals (tobacco use, implied use or appearance of smoking paraphernalia) and brand appearances were measured by 5 min interval coding in the 15 most commercially successful films in the UK each year from 1989 to 2008.

Results Tobacco intervals occurred in $70 \%$ of all films. Over half (56\%) of those that contained tobacco intervals were rated by the BBFC as suitable for viewing by children aged $<15$, and $92 \%$ for people aged $<18$. Tobacco interval appearances fell by $\sim 80 \%$ over the study period, but persisted in films in all BBFC categories. Brand appearances were nearly twice as likely to occur in films originating wholly or in part from the UK (UK films). Specific brands, particularly Marlboro and Silk Cut, appeared in $9 \%$ of all films, and most brand appearances $(39 \%)$ were in films with BBFC 15 classification.

Conclusions Tobacco imagery in the most popular films shown in the UK has declined substantially over the past 20 years but continues to occur, particularly in UK films, and predominantly in films categorised as suitable for viewing by children and young people. Specific brand appearances are now rare but occur repeatedly in some films. The BBFC is not currently protecting children and young people from exposure to tobacco imagery in film.

\section{INTRODUCTION}

Tobacco use causes nearly 5 million deaths worldwide each year, ${ }^{1}$ more than any other avoidable cause, with almost half of all tobacco-related death in the UK being the result of respiratory diseases, predominantly lung cancer and chronic obstructive pulmonary disease (COPD). ${ }^{2}$ With $85 \%$ of all lung cancer deaths and $>80 \%$ of all COPD deaths in England attributable to smoking, ${ }^{2}$ preventing smoking is therefore a paramount public health priority. Since the majority of smokers become addicted in their teens, ${ }^{3}$ measures to prevent exposure of children and young people to tobacco products and positive smoking role models are especially important. Whilst tobacco advertising and sponsorship are now heavily restricted in the $\mathrm{UK}^{4}$ and many other countries, ${ }^{5}$ exposure to tobacco imagery and brand appearances in the media has not been controlled.

It is well established that tobacco companies have used films to promote tobacco products for many years, ${ }^{6}$ and since at least $1927 .^{7}$ Adolescents who view tobacco use in film and who admire leading actors and actresses whose characters smoke in films are more likely to smoke themselves, and are more likely to view smoking favourably. ${ }^{8-10}$ A study from New Zealand reported that adolescents felt that smoking in films was highly prevalent and believed it to be a true representation of reality. ${ }^{11}$ These young people perceived smoking prevalence amongst their peers and adults to be higher than it was. ${ }^{11}$ Beliefs like these can assist in the social normalisation of smoking, which in turn can promote youth initiation. ${ }^{12}$ An exposureresponse relationship between smoking imagery in films and subsequent adolescent smoking behaviour has also been demonstrated. ${ }^{813}$ Given these strong associations and that uptake of smoking has considerable future health implications, exposure to tobacco imagery including branding might be expected to be an important determinant of age classification of films.

This study was therefore carried out to characterise the occurrence of tobacco use and tobacco branding in the most popular films shown in UK cinemas over the past 20 years in relation to year of release, the age certification allocated to the film by the British Board of Film Classification (BBFC), country of origin and other characteristics.

\section{METHODS}

We used listings of the most commercially successful films based on gross UK cinema box office takings data provided by the UK Film Council (UKFC) $)^{14}$ to identify the 15 most popular films viewed in the UK for each year between 1989, the first year that UK-specific figures were collected, and 2008. We obtained DVD copies of the 300 sampled films from rental providers, and viewed and coded them in order of availability. For each film we used DVD package labels, the film credits, the Internet Movie Database (IMDb) ${ }^{15}$ and the $\mathrm{UKFC}^{14}$ to ascertain year of release, run time, age rating of film (as rated by the BBFC, ${ }^{16}$ see table 1 for detail) and country of origin. Film genre was determined from the IMDb categories ${ }^{15}$; where more than one category was listed, the most appropriate single genre was determined at the researcher's discretion.

We developed a coding scheme for all appearances of tobacco or tobacco-related products (tobacco intervals) in these films from previously reported methods, ${ }^{6}{ }^{18-26}$ including the following 
Table 1 British Board of Film Classification (BBFC)* age-rated restriction categories for films viewed in UK cinemas

\begin{tabular}{ll}
\hline Category & Description \\
\hline Universal (U) & Suitable for all audiences \\
Parent Guidance (PG) & $\begin{array}{l}\text { General viewing, but some scenes may be unsuitable } \\
\text { for young children }\end{array}$ \\
$12 / 12 \mathrm{~A} \dagger$ & $\begin{array}{l}\text { (12) Suitable for 12 years and older, (12A) under 12s } \\
\text { must be accompanied by an adult }\end{array}$ \\
15 & $\begin{array}{l}\text { Suitable for 15 years and over } \\
\text { Suitable for } 18 \text { years and older }\end{array}$ \\
\hline
\end{tabular}

*The BBFC is the independent, non-government body funded through fees from films submitted, which classifies films into age categories based on each film's suitability for viewing by the audience to advise local authorities, who license cinemas under the Licensing Act 2003. ${ }^{17}$

†12- and 12A-rated films have been amalgamated since the 12A film rating replaced the 12 rating for cinema film viewing in 2002.

categories: tobacco use, the consumption of any tobacco product on screen by any character; tobacco paraphernalia, the presence on screen of tobacco or related materials (such as cigarette packets, matches, lighters, ashtrays); and inferred tobacco use, the presence of a verbal or non-verbal inference (such as a comment on smoking, leaving a scene with a packet of cigarettes and lighter, or a smoky atmosphere). Brand appearances were defined as the occurrence of branded tobacco products, or of advertisements, logos or other unambiguous brand appearances. We used 5 min interval coding, which has previously been shown to be a sensitive means of detecting relative changes in behaviour levels ${ }^{26}$ and used in studies exploring tobacco use in film. ${ }^{19-21} 2327$ Tobacco use, tobacco paraphernalia and inferred tobacco use were coded as having occurred if observed at least once in any $5 \mathrm{~min}$ coding period. Multiple occurrences in the same category in the same 5 min period were counted as a single event; an occurrence that crossed a transition from one 5 min interval to the next was recorded as two events. Brand appearances were coded in the same way, except that when more than one brand appeared in a single 5 min interval, the total number and identity of different brands observed was recorded. Where identical branding of identical products (or advert, merchandise, etc) occurred in the same 5 min interval they were counted once.

\section{ANALYSIS}

Data were entered into Microsoft Office Excel $^{28}$ as the films were viewed, and analysed using Excel and STATA $10 .^{29}$ The total number of film hours coded, and the mean, SD and range of lengths were obtained using summary statistics in STATA. Tobacco use, tobacco paraphernalia and inferred tobacco use occurrences per hour for each film were calculated by dividing the sum of the tobacco episodes in each category in each film by the length of the film. The mean rate of occurrences in all films for each year was calculated by a similar method, as were total and mean figures for all categories of tobacco intervals combined. Trends of the rate of intervals per hour over time, occurrence of tobacco intervals between different BBFC categories, genres, country of origin and other comparisons were made using standard parametric (linear regression) or nonparametric methods ( $\chi^{2}$ test), as appropriate.

\section{RESULTS}

The 300 films totalled $582.8 \mathrm{~h}$ (34969 min) of film time, with a mean (SD) of 116.7 (24.7) min, and a range from 78 (Inspector Gadget) to 224 (Dances With Wolves) minutes. The BBFC U, PG, 12/12A, 15 and 18 categories contained 15, 27, 26, 26 and $6 \%$, respectively, of films. Most films (94\%) were produced by or in partnership with US producers, and $68 \%$ were produced solely from the US. UK producers were involved in $20 \%$ of films, and were solely responsible for $3 \%$. Other countries were involved in producing 19\% of films, but only one film, Muriel's Wedding, had no UK or USA involvement. The 15 most popular films typically accounted for $\sim 50 \%$ of each year's gross UK cinema box office takings, based on yearly box office takings.

There were a total of 6994 intervals of 5 min (mean 23 per film, range 16-45) in the films. Tobacco intervals occurred in 1151 intervals (17\% of the total) and in 210 (70\%) films. The respective proportions of films containing tobacco intervals in each of the BBFC $U$ (15/46), PG (49/80), 12/12A (59/77), 15 $(69 / 78)$ and $18(16 / 19)$ categories were $33,61,77,88$ and $84 \%$, respectively. Tobacco intervals occurred in $68 \%(192 / 281)$ of all youth-rated films (BBFC 15 and below). In the most popular films over the past 5 years (2004-8), 44\% (33/75) contained at least one interval of tobacco; BBFC U, 19\% (3/16); PG, 28\% $(5 / 18) ; 12 / 12 \mathrm{~A}, 57 \%(16 / 28) ; 15,73 \%(8 / 11)$; and $18,50 \%(1 / 2)$. Of those films of $2004-8$ containing tobacco intervals, $97 \%$ (32/33) were BBFC 15 and lower, and 73\% (24/33) were deemed suitable for those aged under 15 years old. Tobacco interval occurrence, in total or any category except branding, was unrelated to country of origin or genre of film. The mean rate of occurrence of all tobacco intervals fell substantially and significantly $(p<0.05)$ between 1989 and 2008, from 3.5 to 0.6 per hour; similar trends occurred for all categories of tobacco interval (figure 1) (in each case $p<0.05$, except for branding where $p=0.315)$. The occurrence of tobacco intervals in films also fell substantially within all BBFC categories (figure 2).

Tobacco use, predominantly cigarette smoking, occurred in 176 films (59\% of all films); $92 \%(162 / 176)$ of the films containing tobacco use were in BBFC 15 and lower categories, and more than half $(56 \%,(98 / 176))$ in BBFC 12/12A and lower categories. Tobacco use did not occur in any U-rated film released after 1999 (figure 2). Tobacco paraphernalia appeared in 180 ( $60 \%$ of all films) films, typically comprising ashtrays (alone or with other paraphernalia in 64\% (116/180) of films containing paraphernalia episodes), cigarette or other tobacco packs $(62 \%$, $112 / 180)$, lighters $(49 \%, 89 / 180)$ and matches $(26 \%, 46 / 180)$. Inferred tobacco use occurred in 223 episodes in 94 films (31\% of all films), typically as non-verbal inferences (74\%, 70/94). Brand appearances occurred 48 times in 28 (9\% of all films) films, of which $10(36 \%, 10 / 28)$ had UK production involvement; this proportion was significantly higher than that of all films with US production involvement $\left(20 \% ; \chi^{2} \mathrm{p}<0.05\right)$. Brand appearances were most common in BBFC category 15 (39\% of appearances were in this category), and $82 \%$ were certified as suitable for viewing by those under 18. The film with the highest number of branded tobacco intervals was Pulp Fiction (BBFC category 18), with brand appearances in 9 out of 31 intervals, though the predominant brand involved was fictional ('Red Apple') and available only from a movie prop supplier. ${ }^{30}$ The largest number of different brands to appear in any film was 12, in Bridget Jones's Diary (BBFC category 15).

Individual brand intervals occurred a total of 74 times, with Marlboro (21 episodes in 13 films) and Silk Cut (14 episodes in 4 films) being the most frequent (figure 3). Details of appearance by film for these brands are presented in table 2. Marlboro occurred in all BBFC categories except $U$, and with no relationship to country of origin; six Marlboro appearances were in one film, Terminator 3: Rise of the Machines, all within one scene in a US petrol station. Silk Cut appearances all occurred between 1996 and 2004 in films set in the UK and made with UK 
Figure 1 Trends in mean tobacco intervals per hour of film, 1989-2008.

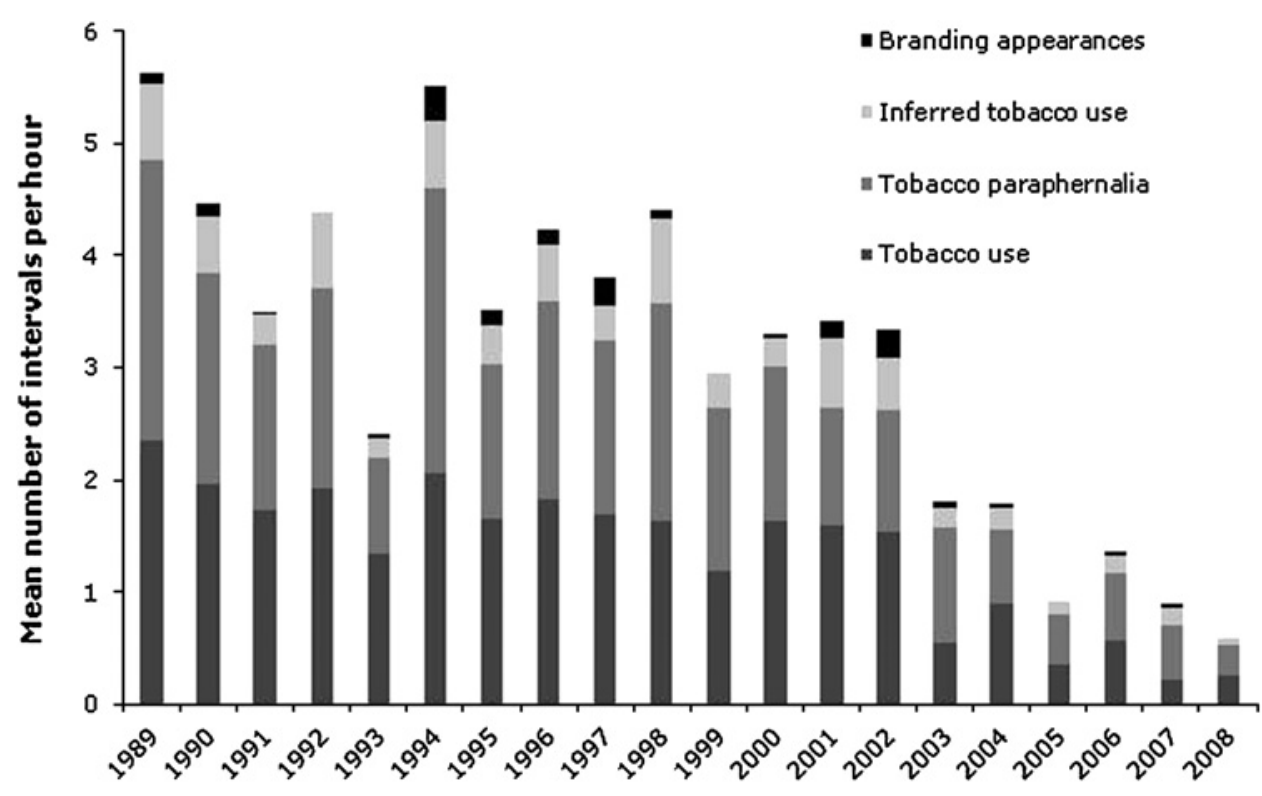

Year film released in the UK

production involvement. The most Silk Cut brand appearances were in Bridget Jones's Diary and About a Boy, both of which were categorised as suitable for youth viewing (BBFC categories 15 and 12, respectively). The lead character in Bridget Jones's Diary (Bridget Jones) smoked Silk Cut regularly throughout the film, as in the novel on which the film was based. ${ }^{31}$ In About a Boy the main character (Will) also smoked Silk Cut regularly throughout the duration of the film, mostly in the presence of a 12-year-old boy. In the novel on which this film was based, ${ }^{32}$ Will smoked infrequently and no brand was identified.
Figure 2 Trends in all tobacco intervals and tobacco use intervals per hour per year by British Board of Film Classification (BBFC) category (all figures expressed as means).
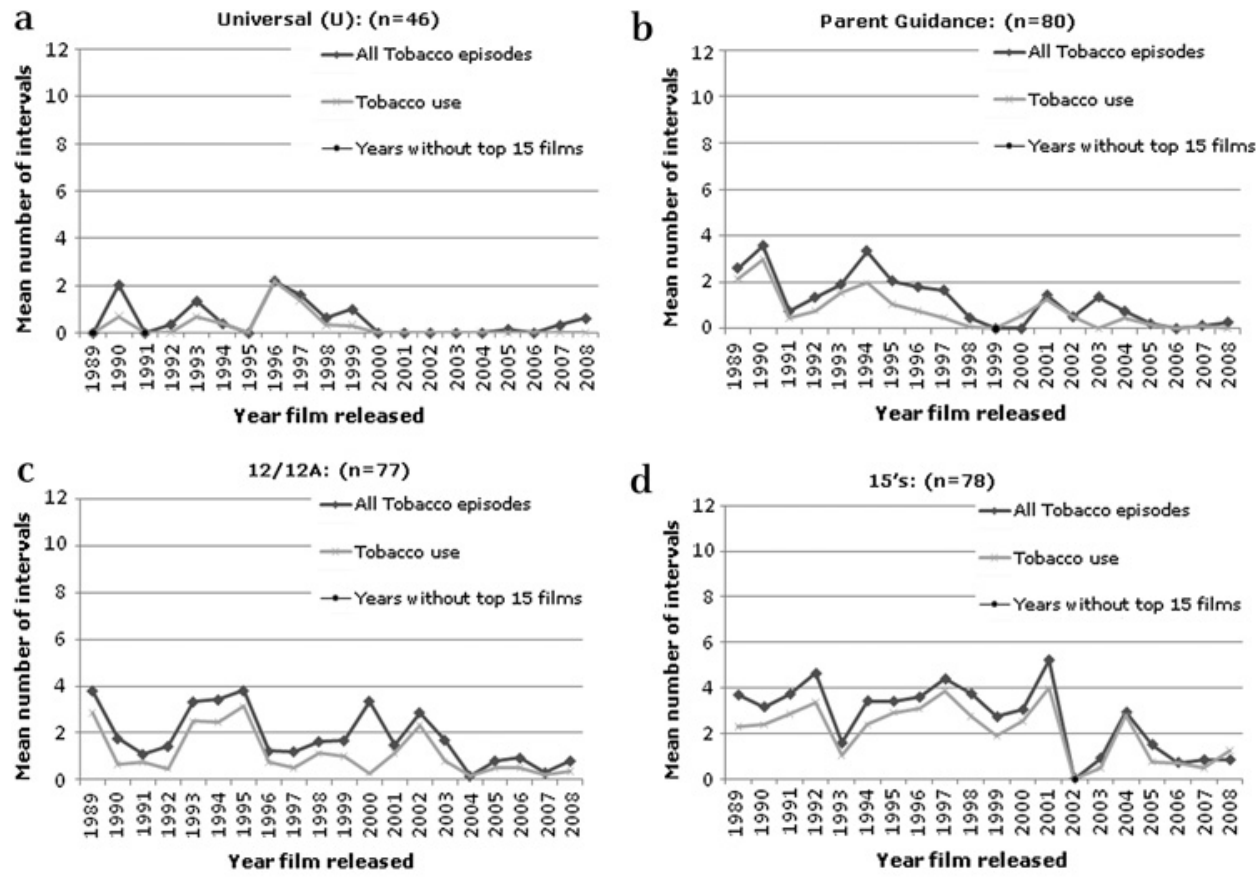

Year film released

d

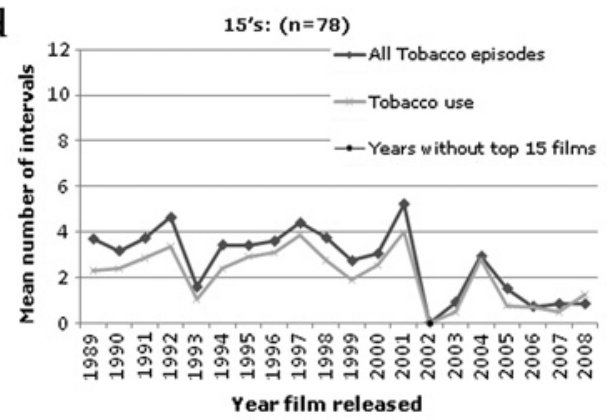

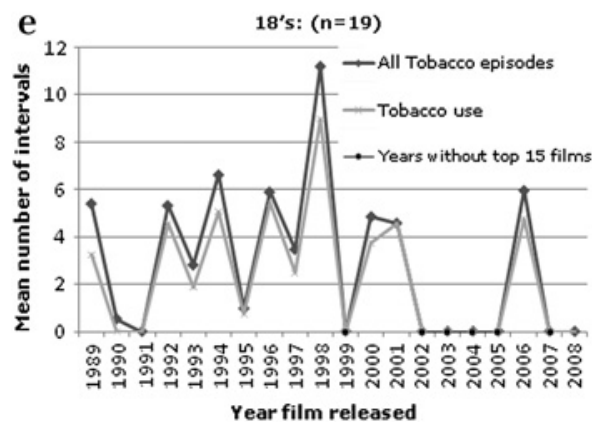




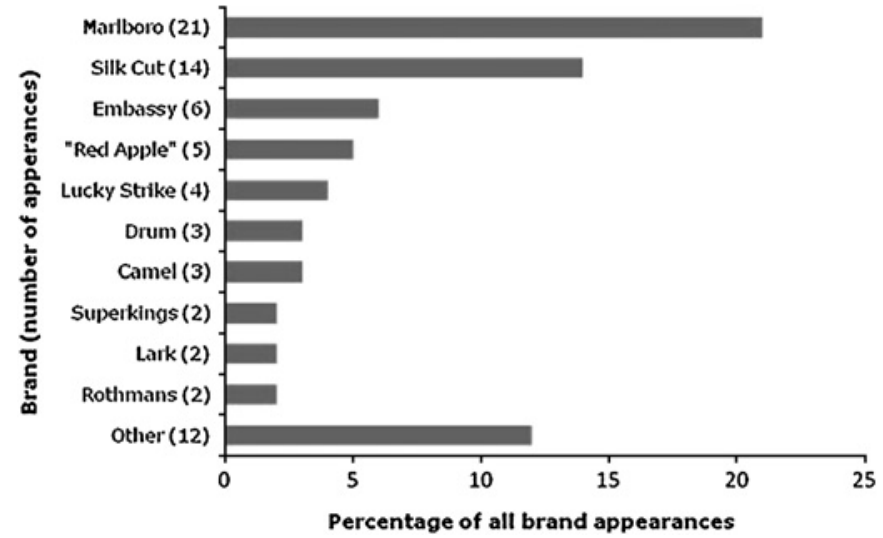

Figure 3 Individual brand intervals in film as percentage of all (74) appearances.

\section{DISCUSSION}

Exposure to tobacco smoking and other forms of tobacco imagery in film is a potent driver of youth and adult smoking, ${ }^{8-10}$ with major consequences for the subsequent health of the smoker such as lung cancer, COPD and pneumonia. ${ }^{2}$ The serious potential hazard represented by tobacco exposure should also be a determinant of film classification, to prevent unnecessary or inappropriate exposure of children and young people to smoking role models. The BBFC guidelines on classification in relation to smoking state only that where '[smoking and tobacco use] feature to a significant extent in works which appeal to children, this will normally be indicated in the Consumer Advice and/or Extended Classification Information.' (p. 12). ${ }^{33}$ Tobacco imagery appears not to have any considerable bearing on the BBFC age classification that a film receives. This study shows that appearances of all types of tobacco intervals in films viewed in the UK has declined substantially over the past 20 years, but that appearances remain common in most of the commercially successful films, and persist to some extent in films in all BBFC categories. It also shows that about two-thirds of films including tobacco intervals are currently classified by the BBFC as suitable for viewing by people aged $<18$, and over half $(61 \%)$ by people aged $<15$. Over the past 5 years $(2004-8)$ the proportion of films containing tobacco deemed suitable for those aged under 18 to watch has increased to $97 \%$.

We found that smoking imagery is also more likely to occur in films that originate wholly or partly in the UK. The specific, repeated occurrence of some brands of cigarette in some films raises the possibility that product placement by tobacco companies is still occurring.

Our study was limited, for logistic reasons, to the top 15 most popular films each year, but, as these typically represent $\sim 50 \%$ or more of total UK annual box office takings, they are likely to reflect the predominant pattern of tobacco exposure in films seen in UK cinemas each year. Coding the occurrence of any behaviour in films is difficult and there is no standardised method; we used an approach that has been widely used in film analysis, ${ }^{19} 212327$ is reliable, ${ }^{19} 2327$ and has been validated as a measure to detect relative changes in levels of behaviour. ${ }^{34}$ The 5 min interval method we used was the same as used by several other researchers, ${ }^{19} 232735$ though other approaches, such as coding scene changes as separate incidents with a 5 min interval approach, ${ }^{21}$ or using $1 \mathrm{~min}$ intervals ${ }^{18}$ or separate scenes to define intervals ${ }^{2026}$ or methods of continuous measurement, ${ }^{22} 2425$ have been described. Like Everett et $\mathrm{al}^{23}$ we divided the number of 5 min intervals by the length of the film to take into consideration the differences in film lengths. The different approaches have relative strengths and weaknesses, but the main impact of their differences will be in the quantification of occurrence frequency. The presence of tobacco intervals, and their relative frequency, is measured by all approaches.

Our finding that tobacco use, imagery and brand appearances are commonplace in films reflects the findings of several previous studies. ${ }^{18-24} 263536$ However, ours is the first study to look at trends over time in appearances, including a wide range of tobacco paraphernalia and inference, and specific brand appearances, in the films most popular with UK audiences. Glantz et $a l^{35}$ limited their definition of 'tobacco usage' to include only smoking or the appearance of ashtrays or advertisements, and Omidvari et a ${ }^{22}$ only actual smoking. Escamilla et a ${ }^{27}$ included other paraphernalia (eg, cigarettes), merchandise and advertising in their investigations. Brand appearances ${ }^{24} 25$ have previously been defined similarly to the definition employed here. Our finding that $70 \%$ of the films viewed contained at least one tobacco interval or brand appearance is consistent with, though slightly lower than, estimates from other studies, most of which explored earlier time periods ${ }^{18-21}$ in which our data show occurrence to have been higher. The difference in results is likely to be explained by the differing time periods investigated.

There is little consensus in previous studies as to whether tobacco and related imagery in film has increased, ${ }^{21}$ stayed the same ${ }^{19}$ or decreased over time. ${ }^{18}$ Our study confirms a fall in the frequency of tobacco intervals in the most popular films viewed in the UK, and that exposure to tobacco use (but not to other imagery) in U-rated films has ceased since 2000. This is both important and encouraging from the point of view of public health, and in large part possibly reflects the impact of the 1998 Master Settlement Agreement ${ }^{37}$ in the USA in 1998, in which the tobacco industry agreed to curtail or cease certain marketing practices in the USA, and after which appearances of tobacco intervals in a study of US films fell by about half. ${ }^{24}$ However, this and the reported decline in brand appearances over a similar period $^{25}$ may have affected predominantly adult-restricted films (BBFC 18). ${ }^{24}$ Others $^{36}$ suggest this may be the result of several factors working together (including a reduction overall in film production, and a producer-distributor shift away from adultrated films). Although the number of brand appearances in our study was small, our other findings suggest that the decline in appearances in general has affected all films; brand appearances still persist in films rated suitable for viewing by children and young people. Titus et $a l^{36}$ also found brand appearances persisting in films, and suggest that they may actually be increasing.

Previous research from the USA on individual brand appearances has identified Marlboro to be the most common brand, ${ }^{2425} 36$ as in the present study, and this perhaps reflects the fact that Marlboro is the market leader in the USA, accounting for $42.4 \%$ of sales. ${ }^{38}$ However Silk Cut holds only $5.2 \%$ of the UK market ${ }^{39}$ and does not have a market share in the USA, so whilst it is not surprising that the brand did not feature in any American film, the strong brand prominence of Silk Cut in two UK films appears disproportionate. Whilst it can be argued that use of Silk Cut was accurate brand translation from book to film in Bridget Jones's Diary, that argument does not justify the brand prominence in About a Boy.

BBFC classification guidelines do not directly refer to tobacco use under the suitability criteria for certifying ratings of films submitted, but do state in $U$ and PG category guidance that films receiving these certifications will show 'No potentially dangerous behaviour which young children are likely to copy' (p. 21). ${ }^{33}$ No reference to tobacco use, smoking or imitable 
Table 2 Films containing the most frequently depicted brands (Marlboro and Silk Cut), by year of UK release, country of origin, British Board of Film Classification (BBFC) certification and number of appearances:

\begin{tabular}{|c|c|c|c|c|}
\hline Title & $\begin{array}{l}\text { Release } \\
\text { year }\end{array}$ & Country of origin & BBFC rating & $\begin{array}{l}\text { Number of } \\
\text { appearances* }\end{array}$ \\
\hline \multicolumn{5}{|l|}{ Marlboro (21 appearances) } \\
\hline See No Evil Hear No Evil & 1989 & USA & 15 & 1 \\
\hline The Commitments & 1991 & Ireland/UK/USA & 15 & 1 \\
\hline Pulp Fiction & 1994 & USA & 18 & 2 \\
\hline Interview With the Vampire & 1995 & USA & 18 & 1 \\
\hline Stargate & 1995 & France/USA & PG & 2 \\
\hline Muriel's Wedding & 1995 & Australia/France & 15 & 1 \\
\hline Men in Black & 1997 & USA & PG & 1 \\
\hline Bean & 1997 & UK/USA & PG & 1 \\
\hline Sleepers & 1997 & USA & 15 & 1 \\
\hline Sliding Doors & 1998 & UK/USA & 15 & 1 \\
\hline Men in Black 2 & 2002 & USA & PG & 2 \\
\hline Terminator 3: Rise of the Machines & 2003 & USA/Germany/UK & $12 \mathrm{~A}$ & 6 \\
\hline The Simpson's Movie & 2007 & USA & $P G$ & 1 \\
\hline \multicolumn{5}{|l|}{ Silk Cut (14 appearances) } \\
\hline Trainspotting & 1996 & UK & 18 & 1 \\
\hline Bridget Jones's Diary & 2000 & UK/France & 15 & 6 \\
\hline About a Boy & 2002 & USA/UK/France/Germany & 12 & 6 \\
\hline Bridget Jones: The Edge of Reason & 2004 & $\begin{array}{l}\text { UK/France/Germany/Ireland/ } \\
\text { USA }\end{array}$ & 15 & 1 \\
\hline
\end{tabular}

* Based on the number of 5 min intervals where branding appears. Where additional forms of the same brand name (cigarettes, advert, billboard, etc) occurred in the same 5 min interval the additional appearances were counted separately.

behaviour is mentioned in either of the other youth-rated age categories (BBFC 12/12A or 15). Given that the BBFC refers specifically to use of drugs, violence, bad language and sex in official guidelines (including strict limitations in youth-rated films), it is surprising, given the extent of the harm caused by smoking and other tobacco use, that these guidelines do not include tobacco.

Most adult smokers first become addicted in their teens ${ }^{3}$ and predominantly do so for psychosocial reasons ${ }^{40}$ such as perceiving it as a sought-after adult behaviour, or as being rebellious. Direct advertising promotes smoking initiation by young people, ${ }^{41}$ and predicts established smoking in young adulthood. ${ }^{42}$ Furthermore, research has linked the presence of tobacco on screen to smoking initiation among young people, ${ }^{8} 94344$ increased positive attitudes towards smoking ${ }^{45}$ and the reinforcement of normative perceptions regarding smoking. On these grounds, some have called for films containing tobacco imagery to be automatically rated for adult viewing only, ${ }^{36} 46-48$ or for antitobacco adverts to be screened before films containing tobacco and for brand identification to be prohibited. ${ }^{49}$ It has been argued that depiction of smoking in films should continue in the interests of factual accuracy and freedom of expression, ${ }^{48}$ yet tobacco depicted in films is rarely factually accurate. ${ }^{12}$ However, these considerations are not mutually exclusive from the need to protect children and young people from imagery, which can easily be achieved by more rational application of BBFC classification, such as ensuring that smoking and other tobacco use be excluded from all youth-rated films (BBFC U, PG, 12/12A, and $15)$, except where an actual historical figure is being represented or where the harms associated with smoking are being shown. ${ }^{12}$ Specific brand exposure can also be avoided by the use of fictional brands, as in the case of 'Red Apple'.

Thus, although smoking imagery and branding images in the most popular films have become substantially less common over the past 20 years, it is apparent that children and young people watching films in the UK are still exposed to frequent and at times specifically branded tobacco imagery, particularly in films originating from the UK. More consistent application of BBFC guidance by the BBFC could dramatically reduce this exposure, and hence protect children and young people from damaging imagery and encourage film makers to avoid tobacco imagery in films intended for younger audiences, without compromising artistic freedoms or factual accuracy.

Funding The UK Centre for Tobacco Control Studies is a UKCRC Centre of Public Health Research Excellence. Funding from the British Heart Foundation, Cancer Research UK, the Economic and Social Research Council, the Medical Research Council and the Department of Health, under the auspices of the UK Clinical Research Collaboration, is gratefully acknowledged.

\section{Competing interests None.}

Provenance and peer review Not commissioned; externally peer reviewed.

\section{REFERENCES}

1. WHO. Why tobacco is a public health priority. Tobacco free initiative. Geneva: World Health Organization, 2008. http://www.who.int/tobacco/health_priority/en/index. html.

2. Twigg L, Moon G, Walker S. The smoking epidemic in England. London: Health Development Agency, 2004. http://www.nice.org.uk/aboutnice/whoweare/ aboutthehda/hdapublications/smoking_epidemic_in_england.jsp.

3. Department of Health. Smoking kil/s: a white paper on tobacco. London: HMSO, 1998. http://www.archive.official-documents.co.uk/document/cm41/4177/4177.htm.

4. The Tobacco Advertising and Promotions Act (Chapter 36). London: HMSO, 2002. http://www.hmso.gov.uk/acts/acts2002/ukpga_20020036_en_1.

5. EU and Directorate General for Health and Consumers. Report on the implementation of the EU tobacco advertising directive. Brussels: Commission of the European Communities, 2008

6. Mekemson C, Glantz SA. How the tobacco industry built its relationship with Hollywood. Tob Control 2002;11Suppl 1:I81-91.

7. Lum KL, Polansky JR, Jackler RK, et al. Signed, sealed and delivered: 'big tobacco' in Hollywood, 1927-1951. Tob Control 2008;17:313-23.

8. Charlesworth A, Glantz SA. Smoking in the movies increases adolescent smoking: a review. Pediatrics 2005;116:1516-28.

9. Thrasher JF, Jackson C, Arillo-Santillan E, et al. Exposure to smoking imagery in popular films and adolescent smoking in Mexico. Am J Prev Med 2008;35:95-102.

10. Dalton MA, Ahrens MB, Sargent JD, et al. Relation between parental restrictions on movies and adolescent use of tobacco and alcohol. Eff Clin Pract 2002;5:1-10.

11. McCool JP, Cameron LD, Petrie KJ. Adolescent perceptions of smoking imagery in film. Soc Sci Med 2001;52:1577-87. 
12. WHO (World Health Organization). Smoke-free movies: from evidence to action. Geneva: World Health Organization, 2009:1-29. http://whqlibdoc.who.int/ publications/2009/9789241597937 eng.pdf.

13. $\mathbf{N C l}$ (National Cancer Institute). The role of the media in promoting and reducing tobacco use Tobacco control Monograph No. 19. Bethesda, MD: US Department of Health and Human Services, National Institute of Health, National Cancer Institute, 2008.

14. UKFC. UK Film Council, 2009. http://www.ukfilmcouncil.org.uk/.

15. IMDb. The Internet Movie Database (IMDb), 2009. http://www.imdb.com/.

16. BBFC. The British Board of Film Classification, 2009. http://www.bbfc.co.uk/.

17. Licensing Act 2003, (Chapter 17). London: HMSO, 2003. http://www.opsi.gov.uk/ acts/acts2003/en/03en17-e.htm.

18. Mekemson C, Glik D, Titus $\mathrm{K}$, et al. Tobacco use in popular movies during the past decade. Tob Control 2004;13:400-2.

19. Hazan AR, Lipton HL, Glantz SA. Popular films do not reflect current tobacco use. Am J Public Health 1994:84:998-1000.

20. Dalton MA, Tickle JJ, Sargent JD, et al. The incidence and context of tobacco use in popular movies from 1988 to 1997. Prev Med 2002:34:516-23.

21. Stockwell TF, Glantz SA. Tobacco use is increasing in popular films. Tob Control 1997;6:282-4

22. Omidvari K, Lessnau K, Kim J, et al. Smoking in contemporary American cinema Chest 2005; 128:746-54

23. Everett SA, Schnuth RL, Tribble JL. Tobacco and alcohol use in top-grossing American films. J Community Health 1998;23:317-24.

24. Adachi-Mejia AM, Dalton MA, Gibson JJ, et al. Tobacco brand appearances in movies before and after the master settlement agreement. JAMA 2005;293:2341-2

25. Sargent JD, Tickle JJ, Beach ML, et al. Brand appearances in contemporary cinema films and contribution to global marketing of cigarettes. Lancet 2001;357:29-32.

26. Worth KA, Dal Cin S, Sargent JD. Prevalence of smoking among major movie characters 1996-2004. Tob Control 2006;15:442-6.

27. Escamilla G, Cradock AL, Kawachi I. Women and smoking in Hollywood movies: a content analysis. Am J Public Health 2000;90:412-4.

28. Microsoft. Microsoft Office Excel 2007 [program], 2007.

29. StataCorp. STATA/SE 10.0 [program]. Texas: StataCorp LP, 2007.

30. PropMasters. Pulp fiction red apple cigarette pack. Kent: Prop Masters, 2009. http://www.propmasters.net/product_info.php?products_id=319.

31. Fielding H. Bridget Jones's diary. London: Pan Macmillan, 1997.

32. Hornby N. About a boy. London: Penguin Books Ltd, 2002.

33. BBFC (British Board of Film Classifications). BBFC the guidelines. London: British Board of Film Classifications, 2009:1-40.
34. Harrop A, Daniels M. Methods of time sampling: a reappraisal of momentary time sampling and partial interval recording. J Appl Behav Anal 1986;19:73-7.

35. Glantz SA, Kacirk KW, McCulloch C. Back to the future: smoking in movies in 2002 compared with 1950 levels. Am J Public Health 2004:94:261-3.

36. Titus K, Polansky JR, Glantz S. Smoking trends in U.S. Movies 1991-2008. Breathe California of Sacramento-Emigrant Trails and the Center for Tobacco Control Research and Education, San Francisco: University of California, 2009:1-42. http:// escholarship.org/uc/item/30q9j424.

37. Master settlement agreement, 1998. http://ag.ca.gov/tobacco/pdf/1msa.pdf.

38. StreetInsider. Highlights from Altria's (MO) 02 conference call: Marlboro market share flat from 01 at 42.4\%. Birmingham (USA): StreetInsider.com, 2009. http:// www.streetinsider.com/Earnings/Highlights + from + Altria\%27s + (M0) +02 + Conference +Call: + Marlboro + Market + Share +Flat +from + 01 + at + 42.4\%25/ 4811202.html.

39. Talking Retail. Silk cut launches menthol addition. London: Metropolis International Group Ltd, 2008. http://www.talkingretail.com/products/product-news/ 11537-silk-cut-launches-menthol-addition.html.

40. Jarvis MJ. Why people smoke. In: Britton J, ed. ABC of smoking cessation. Oxford: Blackwell Publishing \& BMJ Books, 2004:4-6.

41. Wellman RJ, Sugarman DB, DiFranza JR, et al. The extent to which tobacco marketing and tobacco use in films contribute to children's use of tobacco: a metaanalysis. Arch Pediatr Adolesc Med 2006;160:1285-96.

42. Gilpin EA, White MM, Messer $\mathrm{K}$, et al. Receptivity to tobacco advertising and promotions among young adolescents as a predictor of established smoking in young adulthood. Am J Public Health 2007;97:1489-95.

43. Dalton MA, Sargent JD, Beach ML, et al. Effect of viewing smoking in movies on adolescent smoking initiation: a cohort study. Lancet 2003;362:281-5.

44. Sargent JD, Beach ML, Adachi-Mejia AM, et al. Exposure to movie smoking: its relation to smoking initiation among US adolescents. Pediatrics 2005;116:1183-91.

45. Sargent JD, Dalton MA, Beach ML, et al. Viewing tobacco use in movies: does it shape attitudes that mediate adolescent smoking? Am J Prev Med 2002:22:137-45

46. Glantz S. Commentary: smoking in movies: a major problem and a real solution. Lancet 2003;362:258-9.

47. Pechmann C, Shih CF. Smoking scenes in movies and anti-smoking advertisements before movies: effects on youth. J Mark 1999:63:1-13.

48. Chapman S. What should be done about smoking in movies? Tob Control 2008:17:363-367.

49. McCarthy M. Tobacco's long-time adversary takes on Tinseltown. Lance 2001;358:44. 


\section{REFERENCES}

1. Anderson SD. Exercise-induced asthma. In: Kay AB, ed. Allergy and allergic diseases. Oxford: Blackwell Scientific Publications, 1997:672-711.

2. Rundell KW, Im J, Mayers LB, et al. Self-reported symptoms and exercise-induced asthma in the elite athlete. Med Sci Sports Exerc 2001; 33:208-13.

3. Dickinson JW, Whyte GP, McConnell AK, et al. Midexpiratory flow versus FEV1 measurements in the diagnosis of exercise induced asthma in elite athletes. Thorax 2006;61:111-4.

4. Holzer K, Douglass JA. Exercise induced bronchoconstriction in elite athletes: measuring the fall. Thorax 2006;61:94-6.

5. Parsons JP, Mastronarde JG. Exercise-induced bronchoconstriction in athletes. Chest 2005;128:3966-74.

\section{Corrections}

doi:10.1136/thx.2009.122291 corr1

Conway Morris A, Kefala K, Wilkinson $\mathrm{TS}$, et al. Diagnostic importance of pulmonary interleukin-1b and interleukin-8 in ventilator-associated pneumonia. Thorax 2010;65:201-7. This article should have included the note that Dr Kefala was joint first author.
Polverino E, Dambrava P, Cilloniz C, et al. Nursing home-acquired pneumonia: a 10 year single-centre experience. Thorax 2010;65:354-59. The correct affiliation for affiliation 1 should have read "Respiratory Department, Hospital Clinic-IDIBAPS, Barcelona-Spain, Centro de Investigación Biomedica En RedEnfermedades Respiratorias (CibeRes, CB06/06/0028, el Ciberes es una iniciativa del ISCIII) - 2009SGRO http://www.idibapsrespiratoryresearch. org."

doi:10.1136/thx.2009.133108corr1

Millett C, Glantz SA. Assigning an '18' rating to movies with tobacco imagery is essential to reduce youth smoking. Thorax 2010;65:377-8. The authors referred to a paper by McNeil et al; this should have been Lyons et al (Lyons A, McNeill A, Chen Y, et al).
Lyons A, McNeill A, Chen Y, et al. Tobacco and tobacco branding in films most popular in the UK from 1989 to 2008. Thorax 2010;65:417-22. There is an error in figure legend 2 which currently reads "Trends in all tobacco intervals and tobacco use intervals per hour per day by British Board of Film Classification (BBFC) category (all figures expressed as means)." It should have read: "Trends in all tobacco intervals and tobacco use intervals per hour per year by British Board of Film Classification (BBFC) category (all figures expressed as means)."

doi:10.1136/thx.2009.127274corr1

Kemp SV, El Batrawy SH, Harrison RN, et al. Learning curves for endobronchial ultrasound using cusum analysis. Thorax 2010;65:534-8. The author name A Roselli should have read A Rosell. 